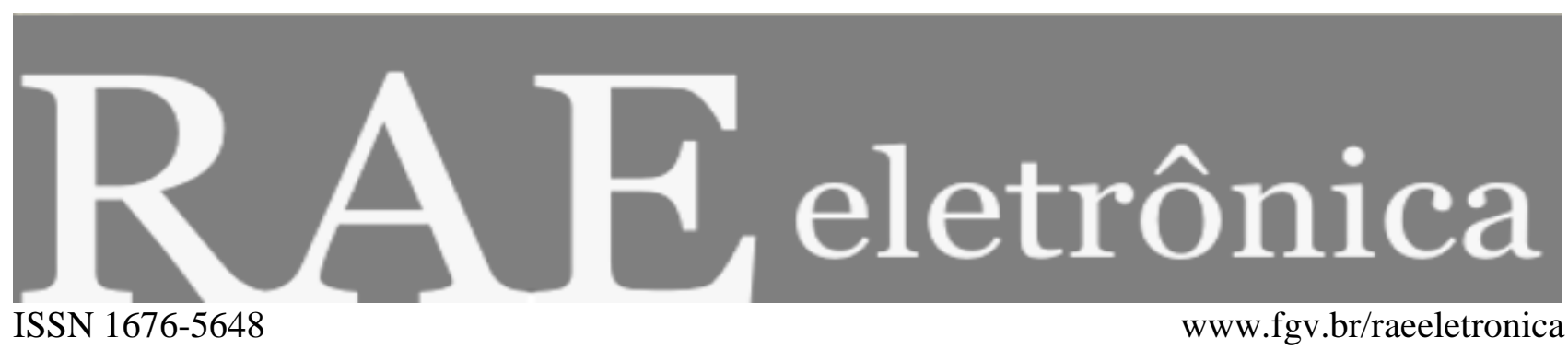

\title{
FÓRUM
}

\section{IDENTIFICAÇÃO DAS DIMENSÕES DA QUALIDADE EM SERVIÇOS: UM ESTUDO APLICADO EM UMA INSTITUIÇÃO DE ENSINO SUPERIOR}

\section{IDENTIFICATION OF THE DIMENSIONS OF THE QUALITY IN SERVICES: A STUDY APPLIED IN AN INSTITUTION OF SUPERIOR EDUCATION}

\section{IDENTIFICACIÓN DE DIMENSIONES DE CALIDAD EN SERVICIOS: UN ESTUDIO APLICADO A UNA INSTITUCIÓN DE ENSEÑANZA SUPERIOR}

\section{Luciene Eberle}

Professora do Centro de Ciências da Administração, Universidade de Caxias do Sul - Caxias do Sul RS, Brasil

leberle@ucs.br

\section{Gabriel Sperandio Milan}

Professor do Centro de Ciências da Administração, Universidade de Caxias do Sul - Caxias do Sul RS, Brasil

gsmilan@ucs.br

\section{Fernanda Lazzari}

Doutoranda em Administração de Empresas pela Escola de Administração, Universidade Federal do Rio Grande do Sul - Porto Alegre - RS, Brasil

ferlazz1@hotmail.com

Recebido em 28.01.2010. Aprovado em 23.06.2010. Disponibilizado em 23.08.2010

Avaliado pelo sistema double blind review

Editor Científico: Organizadores do Fórum de Operações

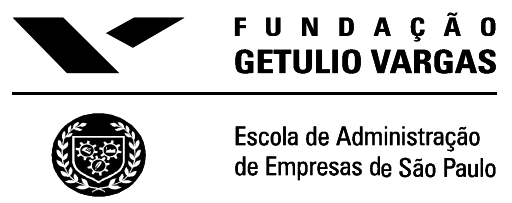




\title{
RESUMO
}

O presente trabalho busca identificar e avaliar a percepção dos clientes (alunos) sobre os serviços de uma Instituição de Ensino Superior (IES) da Serra Gaúcha, no estado do Rio Grande do Sul, por meio da identificação de atributos que têm impacto sobre a satisfação, bem como de dimensões ou fatores relacionados à qualidade, que podem ser sugeridos para a busca de um diferencial competitivo em cursos de pós-graduação (lato sensu). A identificação desses atributos e dimensões pode ajudar a instituição a priorizar ações, considerando a percepção dos alunos, no sentido de elevar a qualidade de seus serviços e estimular a retenção de clientes (alunos), consolidando o posicionamento de mercado da IES. Os resultados obtidos evidenciaram seis dimensões de qualidade de serviços, que podem servir de base a direcionamentos da IES.

PALAVRAS-CHAVES Dimensões da qualidade em serviços, serviços educacionais, satisfação de clientes, retenção de clientes, lealdade de clientes.

\begin{abstract}
This work seeks to identify and assess the perception of customers (students) about the services provided in a Higher Education Institution (HEI) in Serra Gaucha, by identifying the attributes that have an impact on their satisfaction levels and the dimensions or factors related to quality that can be suggested in the search for a competitive differential in post-graduate (specialization) courses. Identification of the attributes and, consequently, the quality dimensions related to the services provided can help the institution prioritize its actions, by taking into consideration student perceptions, in the sense of raising its service quality, thus contributing to excellence in education, as well as customers retention (students) and consolidating its market position. The results showed that there are six quality dimensions in the services provided and they can serve as a basis for the direction to be taken by HEI.
\end{abstract}

KEYWORDS Dimensions of service quality, educational services, customers satisfaction, customers retention, customers loyalty.

RESUMEN El presente trabajo busca identificar y evaluar la percepción de los clientes (alumnos) sobre los servicios prestados en una Institución de Enseñanza Superior (IES) de la Sierra Gaucha, estado de Rio Grande do Sul, a través de la identificación de atributos que ejercen impacto sobre la satisfacción, así como de dimensiones o factores relacionados a la calidad, que pueden ser sugeridos para la busca de un diferencial competitivo en cursos de postgrado (lato sensu). La identificación de dichos atributos y dimensiones puede ayudar a la institución a priorizar acciones, considerando la percepción de los alumnos, en el sentido de elevar la calidad de sus servicios y estimular la retención de clientes (alumnos) y consolidar el posicionamiento de mercado de la IES. Los resultados obtenidos evidenciaron seis dimensiones de calidad de servicios, que pueden servir de base a direccionamientos de la IES.

PALABRAS CLAVE Dimensiones de la calidad en servicios, servicios educacionales, satisfacción de clientes, retención de clientes, lealtad de clientes. 


\section{INTRODUÇÃO}

O desenvolvimento econômico proporcionou o aumento da importância do setor de serviços, que tem gerado uma mudança de comportamento pela conscientização da relevância do ato de servir. Devido às exigências crescentes dos consumidores, as empresas vêm incorporando, em suas culturas organizacionais, a filosofia da "servicilização", que envolve a preocupação com a qualidade, com o atendimento aos clientes e com a pessoalização das atitudes na operação, estando presente a busca constante da satisfação e da retenção dos clientes.

Consoante isso, verifica-se que as instituições de ensino superior (IES) estão cada vez mais preocupadas em avançar no propósito de se tornarem competitivas na percepção de seus clientes, por meio da valorização dos atributos inerentes ao serviço, principalmente no que diz respeito à qualidade de seus cursos e de sua infraestrutura (FREITAS, RODRIGUES, 2003). Nesse sentido, a qualidade na prestação de serviços nas IES tem sido abordada em vários estudos, por diversos autores, no mundo todo, como sendo um fator de consolidação e de crescimento no mercado, pois, para que as instituições sejam competitivas, elas devem fazer um trabalho de excelência na formulação de estratégias e em suas práticas, se quiserem ser bem-sucedidas em mercados de concorrência acirrada (MEYER JR, LOPES, 2004).

As IES oferecem serviços de massa à sua clientela e necessitam ter conhecimento dos principais aspectos que influenciam o processo de tomada de decisão dos alunos potenciais ao escolher uma instituição e seu respectivo curso. Isso exige um monitoramento constante do nível de satisfação dos alunos, para que se consiga retê-los, fazendo com que se sintam parte integrante da instituição e de seus programas (GREY, 2004).

Em um contexto caracterizado pela expansão acelerada (FREITAS, RODRIGUES, 2003) e pela forte competitividade no setor, bem como pelas exigências governamentais e das comunidades onde estão inseridas, as IES têm sentido a necessidade de melhorar a forma como mensuram a qualidade resultante dos serviços prestados, seja como um instrumento voltado à gestão, seja como uma prestação de contas à sociedade e aos órgãos fiscalizadores, como o Ministério da Educação (RODRIGUES, RIBEIRO, MILAN, 2004).

Assim sendo, este trabalho pretende identificar os atributos e as dimensões relacionadas à qualidade dos serviços prestados que impactam a satisfação dos alunos da IES em estudo e que podem vir a contribuir para a retenção de seus alunos na pós-graduação (lato sensu) e em outros programas ofertados pela instituição. 


\section{QUALIDADE EM SERVIÇOS}

No início da década de 1980, começou-se a discutir a qualidade para o setor de serviços, tanto no meio acadêmico quanto no empresarial, buscando-se uma definição que abrangesse as expectativas e as percepções dos clientes e as estratégias organizacionais (GUMMESSON, 1994). De acordo com Parasuraman, Zeithaml e Berry (1985; 1988) e Zeithaml, Parasuraman e Berry (1990), a qualidade em serviços pode ser definida como a amplitude da discrepância entre as percepções (desempenho percebido) e as expectativas dos clientes.

Grönroos (1990) e Fornell (1991) defendem que a definição de qualidade seja feita sob a óptica do cliente, pois o que conta é o que ele percebe como qualidade. Na mesma linha de raciocínio, Gibson (2003) comenta que a orientação para a qualidade se dá a partir do julgamento a respeito da aptidão para a compra ou para o consumo, e que a percepção da qualidade é uma das funções prévias sobre o que os produtos e os serviços devem suprir. Para Albrecht e Bradford (1992), por sua vez, a qualidade em serviços é a capacidade que uma experiência em serviços ou qualquer outro fator relacionado a ela tenha para satisfazer uma necessidade ou um desejo, ou para resolver um problema ou fornecer benefícios a alguém.

Portanto, deve-se fazer uma distinção entre a qualidade dos serviços e a satisfação dos clientes, que são construtos interligados, mas distintos. A qualidade pode ser entendida como a percepção atual do cliente sobre o desempenho do produto ou do serviço, enquanto a satisfação se baseia, também, nas experiências passadas (ANDERSON, FORNELL, LEHMANN, 1992). Além disso, Grönroos (1998) destaca que a qualidade percebida de um serviço é resultante da relação entre percepções e expectativas, sendo um construto anterior à satisfação do cliente, com base no valor atribuído ao nível de qualidade vivenciando.

De acordo com Hudson, Hudson e Miller (2004), a mensuração da qualidade em serviços pelo cliente é feita por meio da comparação das diferenças entre os resultados da percepção (desempenho do serviço) e as suas expectativas (confirmação/desconfirmação), de tal maneira que uma diferença negativa indica qualidade percebida abaixo do esperado, e vice-versa, quando a diferença for positiva (OLIVER, 2009; TURNER, KRIZEK, 2006).

É importante salientar que existem escalas clássicas para mensurar a qualidade em serviços, e, dentre elas, destacam-se a ServQual e a ServPerf. Inclusive, Dutra, Oliveira e Gouveia (2002) afirmam 
FÓRUM - IDENTIFICAÇÃO DAS DIMENSÕES DA QUALIDADE EM SERVIÇOS: UM ESTUDO APLICADO EM UMA INSTITUIÇÃO DE ENSINO SUPERIOR

Luciene Eberle - Gabriel Sperandio Milan - Fernanda Lazzari

que as dimensões da Escala ServQual, adaptadas por Boulding e outros (1993) para o serviço educacional, atendem às características do setor, utilizando as seguintes dimensões de análise: responsividade, confiabilidade, empatia dos professores, segurança e tangibilidade da prestação de serviço, permitindo a mensuração e a categorização para o ambiente de ensino.

No entanto, diversos autores criticaram a Escala ServQual sugerindo a proposição de escalas alternativas que evidenciem a percepção da qualidade dos clientes de forma mais específica ao contexto a ser estudado. Carman (1990) criticou o fato de que não era prático esperar que os usuários de um serviço completassem um inventário de expectativas antes da sua realização, e um inventário de percepções imediatamente após utilizá-lo. Cronin Jr. e Taylor (1992, 1994) e Teas (1993, 1994) também defendem que não há necessidade de aplicar o módulo da escala relativa às expectativas, uma vez que somente a aferição da performance se destaca na mensuração da qualidade percebida. Sendo assim, esses autores desenvolveram a Escala ServPerf, baseada somente na percepção do desempenho dos serviços, que traz como vantagem a redução do instrumento de pesquisa (parcimônia).

A literatura da área parece oferecer defensores para a superioridade da ServPerf em comparação a outros instrumentos mais genéricos (LLUSAR, ZORNOZA, 2000), e essa confirmação da escala foi reforçada pelo trabalho de Brady, Cronin Jr. e Brand (2002), que reaplicaram uma extensão da ServPerf inicial, fortalecendo a importância dessa escala. Eles reafirmam que os proponentes desse instrumento criaram um método alternativo que se baseia no desempenho percebido do serviço, considerando a ordem de casualidade entre a qualidade do serviço e a satisfação do cliente (usuário), justificando que a qualidade não deve ser medida por meio das diferenças entre expectativa e desempenho, e sim como uma percepção que conduz à satisfação de clientes (SIQUEIRA, CARVALHO, 2006).

Em se tratando de qualidade em ensino superior, Rowley (1997) salienta que qualquer tentativa de se medir a qualidade, especificamente, deve levar em consideração as perspectivas das diversas partes interessadas. Srikanthan e Dalrymple (2003) comentam que geralmente os estudos sobre gestão da qualidade nas IES focam a "educação" e esquecem outros fatores que influenciam a percepção dos alunos. Como os principais usuários dos serviços oferecidos pelas IES são os estudantes (MADU, KUEI, 2003), sendo que o mercado é que, provavelmente, irá absorvê-los como profissionais (CHENG, 2000), as IES têm a responsabilidade social de garantir a satisfação de todos os stakeholders envolvidos, e, para tanto, os gestores educacionais precisam desenvolver um sistema de medição válido, confiável e aplicável da qualidade de seus serviços (ROWLEY, 1997; WELSH, DEY, 2002). 


\section{DIMENSÕES E DETERMINANTES DA QUALIDADE EM SERVIÇOS}

Ao se tratar de qualidade, diversos autores acrescentaram alguns elementos às dimensões originais propostas por Garvin (1987), de forma a refletir os desafios dos desempenhos da qualidade percebida colocados aos prestadores de serviços. Das oito dimensões da qualidade de produtos propostas pelo autor, duas delas se encaixam na natureza dos serviços, e são: o desempenho, como benefício primário desejado pelos clientes; e a qualidade percebida, em que a prestação de um serviço exige, muitas vezes, a participação do cliente, originando preocupações ao nível da qualidade da relação (interações) que se estabelece durante o processo de produção e utilização do serviço.

Pelo fato de que os clientes nem sempre possuem informações completas a respeito do provedor de serviços e da própria oferta em si, a qualidade percebida de um serviço pelo cliente é avaliada, basicamente, em duas dimensões: a técnica e a funcional (GRÖNROOS, 1984, 1990). A dimensão técnica diz respeito à qualidade dos resultados desejados pelos clientes, ou seja, "o que" os clientes recebem em suas interações com a organização. Em contrapartida, o usuário também é influenciado pela forma, ou seja, "como" recebe o serviço e como vivencia o processo de produção e consumo simultâneo (PARASURAMAN, ZEITHAML, BERRY, 1985). É válido reforçar, ainda, que a dimensão funcional da qualidade está relacionada às funções do prestador de serviços e às percepções do cliente com o serviço prestado. Já a qualidade técnica aumenta conforme evoluem as percepções totais da qualidade do serviço (DAGGER, SWEENEY, JOHNSON, 2007).

Considerando-se a qualidade em serviços educacionais, e seguindo a abordagem sugerida por Grönroos (1984), que considera duas dimensões, uma que diz respeito aos resultados (técnica) e outra, aos processos (qualidade funcional), Siqueira e Carvalho (2006) sugerem que, no caso da educação superior, a dimensão técnica diz respeito aos conteúdos, à pesquisa e à extensão, enquanto a dimensão funcional deriva dos conhecimentos dos professores, dos pesquisadores ou orientadores, bem como da infraestrutura oferecida aos alunos (prédios, laboratórios e equipamentos).

Alguns autores têm realizado esforços para definir um conjunto genérico de fatores determinantes que seja aplicável a vários tipos de serviço, embora se devam contemplar suas especificidades (CARMAN, 1990). Diversos trabalhos apresentam construtos determinantes da qualidade em serviços, sendo o trabalho desenvolvido por Parasuraman, Zeithaml e Berry (1985) um dos mais relevantes, uma vez que foram considerados os fatores que influenciam a avaliação da qualidade percebida dos clientes, envolvendo tanto a qualidade técnica quanto a qualidade funcional. 
Os cinco determinantes da qualidade em serviços apresentados neste trabalho são: confiabilidade, responsividade, segurança, empatia e tangibilidade.

Por sua vez, Denton (1990) identifica três determinantes da qualidade em serviços: confiabilidade, relacionada à garantia da satisfação dos clientes; responsividade, ligada à resposta imediata (rapidez) ao prestar o serviço esperado pelo cliente; e a unicidade, que é a tarefa de identificar o que os clientes desejam, ou seja, proporcionar uma experiência única para o cliente. Outro estudo a ser considerado é o desenvolvido por Albrecht (1994), que identificou quatro determinantes: cuidado/atenção, espontaneidade, solução de problemas e recuperação de falhas, em que a dimensão funcional foi enfatizada, pois somente a solução de problemas estaria relacionada à dimensão técnica da qualidade.

De outro modo, Johnston (1995) realizou um extenso estudo em que propõe 18 determinantes da qualidade em serviço: acesso, agradabilidade, atenção, disponibilidade, consideração, limpeza e arrumação, conforto, funcionalidade, integridade, confiabilidade, conforto, compromisso, comunicação, competência, cortesia, flexibilidade, amabilidade, responsividade e segurança. Não tendo sido parcimonioso, o que dificulta o entendimento dos limites entre alguns fatores, o autor reconhece tanto a amplitude do tema quanto a evidência de que alguns deles podem predominar em relação aos outros conforme a situação analisada.

Direcionado à educação superior, Hill (1995) relacionou a qualidade com a variabilidade das expectativas dos alunos ao longo de sua vida acadêmica, adotando 16 determinantes da qualidade, que abrangem fatores acadêmicos, financeiros e de acomodação, e que são: acessibilidade, desempenho dos professores, metodologia de ensino, envolvimento do aluno, troca de conhecimentos, possibilidades de consulta, facilidades tecnológicas, acervo da biblioteca, interação entre alunos, livraria universitária, serviços de apoio, serviços financeiros, limpeza dos ambientes, acomodação, instalações físicas, feedback aos problemas, bem-estar, colocações profissionais, formação de carreira profissional, carreira profissional e inserção internacional.

Joseph e Joseph (1997) identificaram sete elementos de medição da qualidade no momento de escolha de uma IES, que são: reputação acadêmica, oportunidades de carreira, programação dos cursos, tempo de duração e custos dos cursos, aspectos físicos, localização da instituição e indicação de terceiros. Já Sohail e Shaikh (2004) afirmam que os fatores determinantes que mais influenciam o nível de qualidade de uma IES são os professores, as evidências físicas e a reputação da IES. 


\section{ENCADEAMENTO ENTRE QUALIDADE PERCEBIDA, SATISFAÇÃO, RETENÇÃo E LEALDADE DE CLIENTES}

Diversos autores definem a satisfação de clientes com o foco na qualidade, pois ambos os conceitos têm sua origem no paradigma da desconfirmação (MARCHETTI, PRADO, 2001). No entanto, a diferença entre os conceitos de qualidade percebida e de satisfação de clientes não encontra unanimidade na literatura. Bloemer e Kasper (1995) e Bolton e Drew (1991) propõem que a qualidade percebida dos serviços é formadora da satisfação de clientes. Em contrapartida, Oliver (2009) faz distinções entre a perspectiva de curto e de longo prazo desses conceitos, destacando que o cliente processa a avaliação da qualidade percebida associada a uma transação específica logo após ter experimentado a compra ou o consumo, tornando-se um antecedente da satisfação.

A satisfação de clientes é primordial para a sobrevivência das empresas. Alguns autores defendem a tese de que a satisfação de clientes deve ser um fator gerenciado, para possibilitar o sucesso das organizações (ANDERSON, FORNELL, LEHMANN, 1994; OLIVER, 2009). Sendo assim, Rossi e Slongo (1998) comentam que obter informações sobre os níveis de satisfação do cliente deve ser prioridade dos gestores naquelas empresas que são comprometidas com a qualidade de seus produtos e serviços e, por conseguinte, com os resultados alcançados junto aos seus clientes. Por decorrência, os investimentos em qualidade devem ser vistos como uma possibilidade de geração de maior lucro e rentabilidade, e não meramente como despesas para a empresa (REICHHELD, SASSER JR, 1990).

De acordo com Fornell (1992), o que se configura como medida de sucesso de uma estratégia baseada na satisfação de clientes é a intenção da retenção que, se bem trabalhada, poderá conduzir à lealdade e, consequentemente, a uma maior lucratividade e rentabilidade para a empresa. Para Kotler e Fox (1994), a retenção de clientes é importante por diversas razões, pois uma instituição orientada para o mercado deseja atingir um nível máximo de satisfação, em que pragmaticamente é menos provável que clientes satisfeitos a abandonem. Consoante isso, Oliver (1999) e Sasser Jr. e Jones (1995) configuram a satisfação de clientes como uma base necessária para a retenção e para a formação de uma possível lealdade de clientes. Em acréscimo, Reichheld (1996) afirma que uma empresa com foco na satisfação é capaz de estreitar relacionamentos com os clientes.

Segundo Vavra e Pruden (1995), o principal fator para o sucesso do novo milênio é a retenção de clientes, considerada como o componente mais importante na consolidação da participação do 
FÓRUM - IDENTIFICAÇÃO DAS DIMENSÕES DA QUALIDADE EM SERVIÇOS: UM ESTUDO APLICADO EM UMA INSTITUIÇÃO DE ENSINO SUPERIOR

Luciene Eberle - Gabriel Sperandio Milan - Fernanda Lazzari

mercado, do volume de negócios, do lucro e da rentabilidade das empresas. Diversos estudos evidenciam a relação entre a satisfação e a retenção de clientes, sendo que o aumento nos níveis de satisfação pode resultar no aumento das intenções de repetição de compra, de consumo ou de utilização de um produto e/ou de um serviço (RUST, ZAHORIK, 1993; ZEITHAML, BERRY, PARASURAMAN, 1996; REICHHELD, MARKEY JR, HOPTON, 2000; GRIFFIN, 2002).

Como um processo de evolução dos conceitos, Oliver (1999) chama a atenção para o que denomina a "queda da dinastia das pesquisas de satisfação", dando ênfase para a retenção e, principalmente, para a lealdade de clientes como estratégia de sustentação do sucesso empresarial. O autor sugere, ainda, que a lealdade deve ser vista como um comprometimento profundo da repetição de compra ou uso da mesma marca, empresa, produtos e/ou serviços, criando barreiras e evitando a migração para concorrência. Nesse horizonte, Milan e Trez (2005) afirmam que a lealdade do cliente é um conceito multidimensional e que incorpora o compromisso do cliente em relação a uma marca.

Pode-se dizer que a qualidade do serviço passa a ser o foco, assim como a satisfação, a confiança entre as partes e o valor, auxiliando no entendimento dos mecanismos que levam à formação da retenção e da lealdade de clientes (ESPARTEL, 2005). Aliás, Milan (2006) defende que o fator impulsionador para as empresas é perceber o encadeamento existente entre a qualidade percebida dos serviços prestados, a satisfação, a retenção e a lealdade dos clientes e, consequentemente, o desempenho do negócio, criando um ciclo virtuoso.

\section{CARACTERIZAÇÃO DO AMBIENTE DE PESQUISA}

A instituição utilizada como ambiente de pesquisa é uma IES situada na Serra Gaúcha. Economicamente, a região é responsável por mais de 17\% do PIB gerado pelo estado do RS (CICS, 2008). Trata-se de uma instituição de caráter comunitário regional, sendo que, atualmente, oferece 41 cursos de graduação com 67 habilitações e 126 opções de ingresso. Oferece, ainda, 61 cursos de pósgraduação lato sensu (especializações e MBAs), e 11 cursos de pós-graduação stricto sensu (mestrados e doutorados). O número total de alunos é de 37.021, sendo que há mais de 1.000 alunos matriculados nos cursos de pós-graduação.

Na década de 1960, a IES iniciou suas atividades de ensino de pós-graduação lato sensu. Os cursos de lato sensu oferecidos nas diversas áreas do conhecimento se solidificaram e apresentaram um crescimento substancial, sobretudo nos anos 1970 e 1980. Esse desempenho foi ainda mais expressivo 
na década de 1990, que apresentou um crescimento de 66,7\% nos cursos de pós-graduação, formação lato sensu (especializações e MBAs).

\section{OBJETIVOS DO TRABALHO}

Os objetivos indicam o que se pretende conhecer, medir ou comprovar no decorrer da investigação ou da pesquisa. Para tanto, o objetivo geral da pesquisa é identificar os atributos e as dimensões relacionadas à qualidade percebida dos serviços prestados pela IES em estudo, no que se refere aos cursos de pós-graduação lato sensu.

Os objetivos específicos têm a função de aprofundar as intenções expressas no objetivo geral. Dessa forma, os objetivos específicos do trabalho são os seguintes:

a) identificar os atributos do serviço que impactam a satisfação dos alunos em relação aos serviços prestados;

b) identificar as dimensões (fatores) que compõem a avaliação da satisfação dos alunos no que diz respeito à qualidade dos serviços prestados;

c) verificar a relação entre a satisfação geral dos alunos e as variáveis analisadas (atributos do serviço); e

d) analisar a possibilidade de recompra de serviços e a indicação da IES a terceiros.

\section{MÉTODO UTILIZADO PARA O ESTUDO}

O método de pesquisa é composto pelo conjunto de processos pelos quais se permite conhecer determinada realidade e está intimamente relacionado aos objetivos a serem investigados, descrevendo cada uma das fases e etapas da pesquisa. Assim, o presente trabalho foi realizado em duas fases: a primeira, caracterizada como uma pesquisa qualitativa, de caráter exploratório; e a segunda, uma pesquisa quantitativa, de caráter conclusivo.

$\mathrm{Na}$ fase qualitativa, foram implementadas entrevistas individuais em profundidade, com uma abordagem semiestruturada, conduzidas mediante a aplicação de um roteiro básico de questões (RIBEIRO, MILAN, 2004), que serviu para orientar as entrevistas, as quais foram aplicadas a 16 entrevistados, não sendo necessária a ampliação dessa etapa de coleta de dados devido à saturação dos 
resultados (WRAY, MARKOVIC, MANDERSON, 2007), uma vez que as respostas dos entrevistados passaram a ser repetitivas, não acrescentando contribuições. O número de entrevistados, portanto, compreendeu cinco colaboradores ligados à pós-graduação lato sensu e 11 alunos de diversos programas do mesmo nível da IES. Valendo-se de suporte no referencial teórico estudado e utilizandose os dados coletados nas entrevistas, realizou-se uma análise de conteúdo (BARDIN, 2004), obtendose uma lista com 49 atributos relevantes a serem incorporados à segunda fase de pesquisa.

$\mathrm{Na}$ fase conclusiva, realizou-se uma pesquisa quantitativa com a aplicação de um questionário estruturado pelo método survey (MALHOTRA, 2006) com a intenção de mensurar a satisfação dos alunos e resultar nas dimensões (fatores) da qualidade dos serviços. Para aferir a satisfação dos alunos, adotou-se uma escala Likert de 7 pontos, contemplando em seus extremos "1. Totalmente insatisfeito" e "7. Totalmente satisfeito". Os questionários foram aplicados em sala de aula, mediante autopreenchimento. Para o tratamento dos dados foram utilizadas técnicas estatísticas multivariadas (HAIR JR. e outros, 2005; JOHNSON, WICHERN, 2002).

\section{Caracterização da amostra}

A população deste estudo foi composta por alunos provenientes de cursos de pós-graduação lato sensu regularmente matriculados. Tendo em vista que, de acordo com a Pró-Reitoria de Pós-Graduação (Relatório 2008), existem 1.015 alunos matriculados em cursos de pós-graduação lato sensu, aplicou-se a pesquisa a uma amostra de 521 alunos, considerando um intervalo de confiança de $95 \%$ e um erro máximo associado de 3\%.

Para tanto, empregou-se uma amostragem estratificada (GATES, MCDANIEL JR, 2005), classificando-se a população em subconjuntos em relação às áreas do conhecimento e seus respectivos cursos, contemplando-se, assim, os fatores relacionados com o comportamento de interesse e o perfil dos alunos das diversas áreas. Após isso, foram determinadas as proporções da população nos diversos subgrupos ou extratos identificados, conforme mostra a Tabela 1.

A partir da coleta de dados, procedeu-se à análise do perfil dos respondentes. Quanto ao gênero (sexo) dos respondentes, houve a predominância do sexo feminino, representando 64,88\% dos respondentes, enquanto as pessoas do sexo masculino representaram 35,12\% da amostra. Em relação à idade, observou-se que a média de idade dos alunos é de 32 anos e o nível de rendimento individual dos respondentes está caracterizado predominantemente entre $\mathrm{R} \$ 700,00$ e $\mathrm{R} \$ 5.000,00$. Quanto à 
FÓRUM - IDENTIFICAÇÃO DAS DIMENSÕES DA QUALIDADE EM SERVIÇOS: UM ESTUDO APLICADO EM UMA INSTITUIÇÃO DE ENSINO SUPERIOR

Luciene Eberle - Gabriel Sperandio Milan - Fernanda Lazzari

instituição onde se graduaram, 70,25\% dos respondentes se formaram na IES em estudo e optaram por nela permanecer, e $29,75 \%$ deles se graduaram em outras instituições.

Tabela 1 - Composição da amostra

\begin{tabular}{|l|c|c|c|}
\hline \multicolumn{1}{|c|}{ ÁREAS DO CONHECIMENTO } & $\begin{array}{c}\text { CURSOS } \\
\text { LATO SENSU }\end{array}$ & $\begin{array}{c}\text { POPULAÇÃO } \\
(\boldsymbol{\%})\end{array}$ & RESPONDENTES \\
\hline Ciências Contábeis, Econômicas e Administrativas & 17 & 38 & 198 \\
\hline Ciências Jurídicas & 04 & 09 & 115 \\
\hline Ciências Humanas e Comunicação & 10 & 22 & 36 \\
\hline Filosofia e Educação & 03 & 07 & 47 \\
\hline Ciências Exatas e Tecnologias & 05 & 11 & 47 \\
\hline Ciências Biológicas e da Saúde & 04 & 09 & 21 \\
\hline Artes e Arquitetura & 02 & 04 & $\mathbf{5 2 1}$ \\
\hline TOTAL & $\mathbf{4 5}$ & $\mathbf{1 0 0}$ & \\
\hline
\end{tabular}

Fonte: Pró-reitoria de pós-graduação e pesquisa (2008).

\section{Processo de coleta dos dados}

Na sequência, a partir da estruturação do questionário de pesquisa foi implementado um pré-teste, ou teste piloto, no qual o instrumento de coleta de dados foi submetido a 10 alunos matriculados em cursos de pós-graduação lato sensu da IES, a fim de se verificar a facilidade de compreensão das perguntas, do preenchimento das respostas e possíveis melhorias (conteúdo e forma) a serem incorporadas.

O processo de coleta de dados foi realizado no mês de setembro de 2008, e, devido aos calendários flexíveis dos cursos, os questionários foram aplicados respeitando e controlando os extratos identificados (Tabela 1). Conforme foram sendo aplicados e recolidos, os questionários foram sendo analisados e processados. Todos os questionários receberam números de controle (código), sendo inspecionados um a um, para a digitação dos dados. Com o banco de dados formatado, realizou-se uma revisão minuciosa e partiu-se para a preparação dos dados e para as análise estatísticas.

\section{TRATAMENTO, ANÁLISE E INTREPRETAÇÃO DOS DADOS}


Após a coleta de dados, a etapa seguinte da pesquisa foi composta pela análise e interpretação dos dados. Os dados da pesquisa foram tabulados com a utilização do Microsoft Excel, e para os procedimentos de estatística descritiva e análises multivariadas foi utilizado o software SPSS 13.0 (Statistical Package for Social Sciences). Antes de analisar os dados da pesquisa, deve ser realizada a preparação dos dados, verificando-se as características e a adequação dos dados coletados, com a intenção de detectar erros de digitação e dados omissos (missings), que poderiam comprometer a qualidade das análises (KUMAR, AAKER, DAY, 1999; COOPER, SCHINDLER, 2003; MALHOTRA, 2006).

Ao se tratar da análise multivariada de dados, é necessário dar atenção aos efeitos dos missings sobre o resultado da pesquisa para minimizar seus efeitos negativos e impactos no tamanho da amostra disponível para a análise. O método utilizado foi a desconsideração dos casos e/ou variáveis que excediam 10\% da amostra com dados omissos (não respostas). Sendo assim, optou-se por eliminar os atributos 01 (acervo), 07 (atendimento), 18 (disponibilidade dos professores em atender os alunos extraclasse), 28 (incentivos de atividades científicas), 41 (reconhecimento do curso no mercado) e 49 (volume de atividades extraclasse). Além disso, empregou-se o método de atribuição, por meio da substituição pelo valor médio da variável nas respostas "não sei" remanescentes no banco de dados. Para tanto, foram calculadas as médias de cada variável e substituídos os valores omissos de acordo com a alternativa proposta por Hair Jr. e outros (2005).

\section{Identificação das dimensões da qualidade (fatores)}

Para identificar as dimensões da qualidade dos serviços em estudo, foi implementada a análise fatorial, que visa identificar os construtos ou dimensões básicas relacionadas aos dados e para reduzir o número de dimensões de análise (KUMAR, AAKER, DAY, 1999). Com o intuito de facilitar a interpretação dos fatores, foi empregado o método de componentes principais com rotação ortogonal de fatores, a rotação Varimax, minimizando o número de variáveis com cargas altas sobre um fator, reforçando a interpretação deles (MALHOTRA, 2006; KUMAR, AAKER, DAY, 1999; MILAN, TREZ, 2005; MILAN, TREZ, MAIOLI, 2005) por meio da maximização das variâncias das cargas dos fatores (JOHNSON, WICHERN, 2002), o que evidenciou que a matriz de correlações é adequada à técnica de análise escolhida. 
Ao se definirem os fatores, adotou-se o autovalor (eigenvalue) igual ou superior a 1 , sem definição prévia do número de fatores e cargas fatoriais iguais ou superiores a 0,30 , devido ao tamanho da amostra, superior a 350 casos válidos, conforme mostra a Tabela 2.

Tabela 2 - Fatores e seus respectivos autovalores

\begin{tabular}{|c|c|c|c|}
\hline \multirow{2}{*}{ FATORES } & \multicolumn{3}{|c|}{ AUTOVALORES (EIGENVALUES) } \\
\cline { 2 - 4 } & TOTAL & \% DE VARIÂNCIA & \% CUMULATIVO \\
\hline F1 & 17,795 & 44,489 & 44,489 \\
\hline F2 & 2,293 & 5,733 & 50,222 \\
\hline F3 & 1,695 & 4,237 & 54,458 \\
\hline F4 & 1,346 & 3,365 & 57,824 \\
\hline F5 & 1,148 & 2,869 & 60,693 \\
\hline F6 & 1,053 & 2,634 & 63,326 \\
\hline
\end{tabular}

Pela Análise Fatorial Exploratória, verificou-se que as variáveis eram melhor agrupadas em seis fatores; em seguida, realizou-se a Análise Fatorial Confirmatória, com os seis fatores, conforme as cargas fatoriais (correlação entre as variáveis e os fatores) (HAIR JR. e outros, 2005). Cabe ressaltar que foram necessárias algumas adequações dos atributos em relação aos fatores identificados, considerando-se as suas cargas, para uma disposição mais apropriada de acordo com o seu conteúdo ou significado (HAIR JR. e outros, 2005). O atributo agilidade dos serviços de apoio foi reposicionado do F5 $(0,606)$ para o F4 $(0,439)$ por estar mais relacionado ao construto "Atendimento" do que ao construto "Ambiente"; e o atributo carga horária das disciplinas foi reposicionado do F4 $(0,478)$ para o F1 $(0,450)$ devido à proximidade com o construto "Professores / Nível de ensino". As dimensões ou fatores identificados, com seus respectivos atributos, são apresentados na Tabela 3.

Para verificar se os dados poderiam ser analisados pela análise fatorial, procederam-se aos testes de adequação da amostra, mais especificamente o teste KMO (Kaiser-Meyer-Olkin) e o teste de esfericidade de Bartlett. Esses testes fornecem a probabilidade estatística de que a matriz de dados utilizada tenha correlações significativas entre as variáveis (PESTANA, GAGEIRO, 2005). De acordo com os resultados de ambos os testes, apresentados na Tabela 4, observou-se que a análise fatorial é uma técnica adequada ao presente estudo. 
Tabela 3 - Fatores identificados (dimensões da qualidade) e seus respectivos atributos

(continua)

\begin{tabular}{|c|c|c|c|c|c|c|c|}
\hline FATORES & ATRIBUTOS DO SERVIÇO & $\begin{array}{c}\text { FATOR } \\
1 \\
(44,49 \%) \\
\end{array}$ & $\begin{array}{c}\text { FATOR } \\
2 \\
(5,73 \%) \\
\end{array}$ & $\begin{array}{c}\text { FATOR } \\
3 \\
(4,24 \%) \\
\end{array}$ & $\begin{array}{c}\text { FATOR } \\
4 \\
(3,36 \%) \\
\end{array}$ & $\begin{array}{c}\text { FATOR } \\
5 \\
(2,87 \%) \\
\end{array}$ & $\begin{array}{c}\text { FATOR } \\
6 \\
(2,63 \%) \\
\end{array}$ \\
\hline \multirow{12}{*}{$\begin{array}{c}\text { F1 - } \\
\text { Professores/ } \\
\text { Nível de ensino }\end{array}$} & $\begin{array}{l}14 \text { - desempenho dos } \\
\text { professores }\end{array}$ & 0,733 & & & & & \\
\hline & $\begin{array}{l}22 \text { - habilidade dos } \\
\text { professores em despertar } \\
\text { o interesse }\end{array}$ & 0,695 & & & & & \\
\hline & $\begin{array}{l}17 \text { - equilíbrio entre teoria } \\
\text { e prática }\end{array}$ & 0,693 & & & & & \\
\hline & $\begin{array}{l}16 \text { - domínio de professores } \\
\text { dos conteúdos }\end{array}$ & 0,680 & & & & & \\
\hline & $\begin{array}{l}32 \text { - qualidade das } \\
\text { disciplinas do curso }\end{array}$ & 0,657 & & & & & \\
\hline & $\begin{array}{l}05 \text { - aplicabilidade dos } \\
\text { conhecimentos }\end{array}$ & 0,585 & & & & & \\
\hline & $\begin{array}{l}06 \text { - atualidade dos } \\
\text { conteúdos abordados }\end{array}$ & 0,581 & & & & & \\
\hline & $\begin{array}{l}24 \text { - integração entre } \\
\text { as disciplinas do curso }\end{array}$ & 0,565 & & & & & \\
\hline & $\begin{array}{l}39 \text { - titulação dos } \\
\text { professores }\end{array}$ & 0,549 & & & & & \\
\hline & $\begin{array}{l}33 \text { - qualidade do material } \\
\text { de apoio }\end{array}$ & 0,489 & & & & & \\
\hline & $\begin{array}{l}13 \text { - cumprimento do } \\
\text { programada disciplina }\end{array}$ & 0,444 & & & & & \\
\hline & $\begin{array}{l}07 \text { - carga horária } \\
\text { das disciplinas }\end{array}$ & 0,450 & & & 0,478 & & \\
\hline \multirow{7}{*}{$\begin{array}{c}\mathrm{F} 2- \\
\text { Estrutura/ } \\
\text { imagem }\end{array}$} & 36 - reputação da instituição & & 0,721 & & & & \\
\hline & $\begin{array}{l}37 \text { - segurança nas } \\
\text { instalações da instituição }\end{array}$ & & 0,698 & & & & \\
\hline & $\begin{array}{l}26 \text { - localização da } \\
\text { instituição }\end{array}$ & & 0,594 & & & & \\
\hline & $\begin{array}{l}23 \text { - imagem da marca } \\
\text { da instituição }\end{array}$ & & 0,560 & & & & \\
\hline & $\begin{array}{l}28 \text { - outros serviços da } \\
\text { instituição }\end{array}$ & & 0,549 & & & & \\
\hline & $\begin{array}{l}34 \text { - relacionamento entre } \\
\text { os alunos }\end{array}$ & & 0,532 & & & & \\
\hline & $\begin{array}{l}40 \text { - troca de ideias entre } \\
\text { coordenação, professores } \\
\text { e alunos }\end{array}$ & & 0,521 & & & & \\
\hline
\end{tabular}




\begin{tabular}{|c|c|c|c|c|c|c|}
\hline & $\begin{array}{l}35 \text { - relevância das } \\
\text { disciplinas que } \\
\text { compreendem o curso }\end{array}$ & 0,504 & & & & \\
\hline & $\begin{array}{l}38 \text { - processo seletivo ao } \\
\text { curso }\end{array}$ & 0,417 & & & & \\
\hline & $\begin{array}{l}29 \text { - pontualidade dos } \\
\text { professores }\end{array}$ & 0,350 & & & & \\
\hline \multirow{6}{*}{$\begin{array}{c}\text { F3 - } \\
\text { Planejamento e } \\
\text { desenvolvimento } \\
\text { do curso }\end{array}$} & $\begin{array}{l}15 \text { - disponibilidade da } \\
\text { coordenação do curso }\end{array}$ & & 0,783 & & & \\
\hline & $\begin{array}{l}09 \text { - confiança na } \\
\text { coordenação do curso }\end{array}$ & & 0,759 & & & \\
\hline & $\begin{array}{l}21 \text { - habilidade da } \\
\text { coordenação na solução } \\
\text { de problemas }\end{array}$ & & 0,733 & & & \\
\hline & $\begin{array}{l}31 \text { - preocupação da } \\
\text { coordenação quanto } \\
\text { à qualidade do curso }\end{array}$ & & 0,663 & & & \\
\hline & $\begin{array}{l}25 \text { - integração entre } \\
\text { coordenação, professores } \\
\text { e alunos }\end{array}$ & & 0,644 & & & \\
\hline & $\begin{array}{l}27 \text { - manutenção do } \\
\text { calendário das disciplinas }\end{array}$ & & 0,514 & & & \\
\hline \multirow{5}{*}{$\begin{array}{c}\mathrm{F} 4- \\
\text { Atendimento }\end{array}$} & $\begin{array}{l}12 \text { - cordialidade dos } \\
\text { funcionários }\end{array}$ & & & 0,677 & & \\
\hline & $\begin{array}{l}10 \text { - confiança nos } \\
\text { funcionários }\end{array}$ & & & 0,664 & & \\
\hline & $\begin{array}{l}08 \text { - competência dos } \\
\text { funcionários }\end{array}$ & & & 0,659 & & \\
\hline & $\begin{array}{l}11 \text { - conveniência horário } \\
\text { de aulas }\end{array}$ & & & 0,514 & & \\
\hline & $\begin{array}{l}03 \text { - agilidade dos serviços } \\
\text { de apoio }\end{array}$ & & & 0,439 & 0,606 & \\
\hline \multirow{4}{*}{$\begin{array}{c}\text { F5 - } \\
\text { Ambiente de } \\
\text { ensino }\end{array}$} & $\begin{array}{l}02 \text { - adequação das salas } \\
\text { de aulas }\end{array}$ & & & & 0,767 & \\
\hline & $\begin{array}{l}04 \text { - ambiente propício } \\
\text { ao estudo }\end{array}$ & & & & 0,688 & \\
\hline & 18 - equipamentos & & & & 0,651 & \\
\hline & $\begin{array}{l}01 \text { - acesso aos serviços } \\
\text { prestados }\end{array}$ & & & & 0,493 & \\
\hline \multirow{3}{*}{$\begin{array}{l}\text { F6 - Relação } \\
\text { custo versus } \\
\text { benefícios }\end{array}$} & 20 - forma de pagamento & & & & & 0,714 \\
\hline & $\begin{array}{l}19 \text { - estacionamento na } \\
\text { instituição }\end{array}$ & & & & & 0,677 \\
\hline & $30-$ preço & & & & & 0,675 \\
\hline
\end{tabular}


FÓRUM - IDENTIFICAÇÃO DAS DIMENSÕES DA QUALIDADE EM SERVIÇOS: UM ESTUDO APLICADO EM UMA INSTITUIÇÃO DE ENSINO SUPERIOR

Luciene Eberle - Gabriel Sperandio Milan - Fernanda Lazzari

Tabela 4 - Teste KMO e de esfericidade de Bartlett

\begin{tabular}{|c|l|c|}
\hline \multicolumn{2}{|c|}{ TESTE DE ADEQUAÇÃO DA AMOSTRA } & MEDIDAS \\
\hline KMO (Kaiser-Meyer-Olkin) & 0,963 \\
\hline \multirow{3}{*}{ Teste de esfericidade de Bartlett } & Qui quadrado aproximado & 14139,323 \\
\cline { 2 - 3 } & Graus de liberdade & 780 \\
\cline { 2 - 3 } & Significância & 0,000 \\
\hline
\end{tabular}

Para avaliar a confiabilidade das medidas e a consistência interna dos dados, foi utilizado o coeficiente alfa de Cronbach. Os coeficientes de todos os seis fatores ou dimensões da qualidade identificadas ficaram superiores a 0,7 (CHURCHILL JR, 1979; HAIR JR. e outros, 2005), sendo considerados satisfatórios. Como se caracteriza como uma medida que tende a ser "inflada" pela forma como trata as variâncias dos erros associadas aos indicadores, tornando-o uma medida de confiabilidade menos defensável (FINN, 2000; RAYKOV, 1998), optou-se também pela aferição da confiabilidade composta, sendo que, como critério, valores iguais ou superiores a 0,70 são aceitáveis (HAIR JR. e outros, 2005). A Tabela 5 é elucidativa.

Tabela 5 - Alfa de Cronbach e confiabilidade composta para os fatores identificados

\begin{tabular}{|l|l|c|c|}
\hline FS & \multicolumn{1}{|c|}{ FATORES IDENTIFICADOS } & $\begin{array}{c}\text { ALFA DE } \\
\text { CRONBACH }\end{array}$ & $\begin{array}{c}\text { CONFIABILIDADE } \\
\text { COMPOSTA }\end{array}$ \\
\hline F1 & Professores / Nível de ensino & 0,952 & 0,869 \\
\hline F2 & Estrutura / Imagem & 0,896 & 0,811 \\
\hline F3 & Planejamento e desenvolvimento do curso & 0,914 & 0,842 \\
\hline F3 & Atendimento & 0,831 & 0,725 \\
\hline F5 & Ambiente de ensino & 0,847 & 0,780 \\
\hline F6 & Relação custo versus benefícios & 0,701 & 0,730 \\
\hline
\end{tabular}

\section{RELAÇÃO ENTRE A SATISFAÇÃO GERAL E AS DIMENSÕES DA QUALIDADE DO SERVIÇO}

Para avaliar a relação entre a satisfação geral dos alunos e os seis fatores identificados (dimensões da qualidade do serviço) por meio da análise fatorial, foi empregada a Regressão Linear, que tem como objetivo prever uma única variável dependente entre duas ou mais variáveis independentes. Para tanto, 
ao final do questionário, os respondentes atribuíram um grau entre "1. Totalmente insatisfeito" e "7. Totalmente satisfeito" em relação à sua satisfação geral com os cursos de pós-graduação lato sensu da IES.

Por meio do Modelo 1 gerado, pôde-se verificar que os seis fatores são capazes de gerar um índice de explicação de 64,8\%. Os coeficientes e os graus de significância de cada variável independente (fatores) podem ser observados na Tabela 6.

\section{Tabela 6 - Resultado da regressão da satisfação geral}

\begin{tabular}{|l|c|c|c|c|}
\hline \multirow{2}{*}{ FATORES OU DIMENSÕES IDENTIFICADOS } & \multicolumn{2}{c|}{ MODELO 1 } & \multicolumn{2}{c|}{ MODELO 2 } \\
\cline { 2 - 5 } & COEF. & SIG. & COEF. & SIG. \\
\hline Constante & $-0,666$ & 0,001 & $-0,649$ & 0,001 \\
\hline Professores / Nível de ensino (F1) & 0,358 & 0,000 & 0,380 & 0,000 \\
\hline Estrutura / Imagem (F2) & 0,467 & 0,000 & 0,497 & 0,000 \\
\hline Planejamento e desenvolvimento do curso (F3) & 0,005 & 0,905 & - & - \\
\hline Atendimento (F4) & 0,047 & 0,278 & - & - \\
\hline Ambiente de ensino (F5) & 0,152 & 0,000 & 0,179 & 0,000 \\
\hline Relação custo versus benefícios (F6) & 0,033 & 0,235 & - & - \\
\hline
\end{tabular}

No entanto, conforme a Tabela 6, os coeficientes relativos aos fatores F3, F4 e F6 demonstraram-se não significativos a um nível de significância de 0,05. Por este motivo, optou-se por formular um novo modelo de regressão linear, que apresentasse apenas as variáveis (fatores) com grau de significância inferior a 0,05 .

O novo modelo de regressão linear (Modelo 2) apresentou coeficientes significativos para todas as variáveis analisadas, e, apesar da retirada dos fatores F3, F4 e F6, o índice de explicação ficou em $64,6 \%$, reduzindo-se apenas $0,02 \%$ em relação ao modelo anterior. Com isso, é possível perceber que a explicação auferida por meio dos fatores F3, F4 e F6 é explicada pelas outras variáveis (fatores) presentes no modelo. Dessa forma, o modelo que explica a satisfação geral dos alunos (SG) pode ser representado pela seguinte equação:

$$
\mathrm{SG}=-0,649+0,380(\mathrm{~F} 1)+0,497(\mathrm{~F} 2)+0,179(\mathrm{~F} 5)
$$




\section{POSSIBILIDADE DE RECOMPRA E INDICAÇÃO DA IES A TERCEIROS}

Quanto à possibilidade de recompra de serviços e da indicação da IES a terceiros, no questionário de pesquisa, os respondentes atribuíram um grau entre "1. Discordo totalmente" e "7. Concordo totalmente". Dando continuidade à análise de regressão múltipla, inicialmente buscou-se identificar a relação entre a possibilidade de recompra de serviços e os fatores identificados na análise fatorial. A regressão realizada com os seis fatores resultou em um modelo (Modelo 1) com índice de explicação de 47,2\%. Os coeficientes e os graus de significância podem ser observados na Tabela 7.

\section{Tabela 7 - Resultado da regressão da possibilidade de recompra de serviços}

\begin{tabular}{|l|c|c|c|c|}
\hline \multicolumn{1}{|c|}{ FATORES OU DIMENSÕES IDENTIFICADOS } & \multicolumn{2}{c|}{ MODELO 1 } & \multicolumn{2}{c|}{ MODELO 2 } \\
\cline { 2 - 5 } & COEF. & SIG. & COEF. & SIG. \\
\hline Constante & $-1,664$ & 0,000 & $-1,675$ & 0,000 \\
\hline Professores / Nível de ensino (F1) & 0,408 & 0,000 & 0,417 & 0,000 \\
\hline Estrutura / Imagem (F2) & 0,569 & 0,000 & 0,610 & 0,000 \\
\hline Planejamento e desenvolvimento do curso (F3) & 0,003 & 0,961 & - & - \\
\hline Atendimento (F4) & 0,006 & 0,931 & - & - \\
\hline Ambiente de ensino (F5) & 0,185 & 0,003 & 0,198 & 0,000 \\
\hline Relação custo versus benefícios (F6) & 0,035 & 0,443 & - & - \\
\hline
\end{tabular}

Novamente, observou-se que os coeficientes relativos aos fatores F3, F4 e F6 demonstraram-se não significativos a um nível de significância de 0,05. Dessa forma, optou-se por gerar um novo modelo de regressão (Modelo 2) apenas com as variáveis (fatores) que apresentaram grau de significância inferior a 0,05 .

O Modelo 2 apresentou coeficientes significativos para todas as variáveis analisadas, e, apesar da retirada dos três fatores, o índice de explicação teve uma redução de apenas $0,01 \%$, ficando em $47,1 \%$. Sendo assim, o modelo que melhor explica a possibilidade de recompra de serviços da IES (PR) pode ser representado pela seguinte equação:

$$
\mathrm{PR}=-1,675+0,417(\mathrm{~F} 1)+0,610(\mathrm{~F} 2)+0,198(\mathrm{~F} 5)
$$


Na sequência, também foi realizada a análise de regressão para a possibilidade de indicação da IES a terceiros, resultando em um modelo (Modelo 1) com capacidade de explicação de $49 \%$ e cujos coeficientes e graus de significância podem ser vistos na Tabela 8.

Tabela 8 - Resultado da regressão da possibilidade de indicação da IES a terceiros

\begin{tabular}{|l|c|c|c|c|}
\hline \multicolumn{1}{|c|}{ Fatores ou dimensões identificados } & \multicolumn{2}{c|}{ Modelo 1 } & \multicolumn{2}{c|}{ Modelo 2 } \\
\cline { 2 - 5 } & Coef. & Sig. & Coef. & Sig. \\
\hline Constante & $-1,204$ & 0,000 & $-1,242$ & 0,000 \\
\hline Professores / Nível de ensino (F1) & 0,402 & 0,000 & 0,400 & 0,000 \\
\hline Estrutura / Imagem (F2) & 0,593 & 0,000 & 0,608 & 0,000 \\
\hline Planejamento e desenvolvimento do curso (F3) & $-0,001$ & 0,992 & - & - \\
\hline Atendimento (F4) & $-0,027$ & 0,686 & - & - \\
\hline Ambiente de ensino (F5) & 0,158 & 0,006 & 0,162 & 0,002 \\
\hline Relação custo versus benefícios (F6) & 0,044 & 0,294 & - & - \\
\hline
\end{tabular}

Como nas regressões para satisfação geral e possibilidade de recompra, na regressão para indicação a terceiros também se observou que os coeficientes relativos aos fatores F3, F4 e F6 demonstraram-se não significativos a um nível de significância de 0,05. Diante disso, procedeu-se como nos outros casos, gerando um novo modelo de regressão (Modelo 2) em que foram consideradas apenas as variáveis (fatores) que apresentaram grau de significância inferior a 0,05.

O novo modelo (Modelo 2) apresentou coeficientes significativos para todas as variáveis analisadas, e, mesmo com a retirada dos três fatores, o índice de explicação teve uma redução de apenas $0,01 \%$, ficando em $48,9 \%$. Dessa forma, o modelo que melhor explica a possibilidade de indicação da IES a terceiros (IT) pode ser representado pela seguinte equação:

$$
\mathrm{IT}=-1,242+0,400(\mathrm{~F} 1)+0,508(\mathrm{~F} 2)+0,162(\mathrm{~F} 5)
$$

\section{CONSIDERAÇÕES FINAIS}

Como o atual cenário vislumbra o aumento de competição entre as IES para atrair e manter alunos, o conhecimento sobre as suas preferências e sobre as dimensões da qualidade dos serviços prestados 
pode contribuir na definição de estratégias para uma gestão mais efetiva, visando um melhor desempenho no mercado onde estão inseridas (FREITAS, RODRIGUES, 2003; RODRIGUES, RIBEIRO, MILAN, 2004), partindo do pressuposto de que alunos satisfeitos têm maior probabilidade de permanecer na IES e de indicá-la a terceiros.

Nessa direção, o presente trabalho se propôs a identificar as dimensões da qualidade com o intuito de direcionar os esforços para a adequação das necessidades e expectativas dos alunos, direcionando a tomada de decisão por parte dos gestores. Verificando a importância do tema e a escassez de estudos aplicados ao contexto, este estudo teve como objetivo geral identificar os atributos e as dimensões relacionadas à qualidade percebida dos serviços prestados pela IES em estudo, no que se refere aos cursos de pós-graduação lato sensu. É válido destacar que não se partiu de nenhum instrumento a priori, como, por exemplo, as escalas ServQual e ServPerf, com a intenção de desenvolver um instrumento que considerasse as peculiaridades da IES em estudo.

Por conseguinte, foram identificadas seis dimensões (ou fatores) da qualidade dos serviços. As variáveis que se encontraram no primeiro fator (F1), "Professores / Ensino", dizem respeito à qualidade do ensino e estão relacionadas diretamente com o construto "confiabilidade", proposto por Parasuraman, Zeithaml e Berry (1985), dimensão essa que aborda a capacidade de prestar o serviço prometido de forma confiável, relacionando-se, também, com a possibilidade em garantir a satisfação dos clientes (DENTON, 1990).

O segundo fator (F2), denominado "Estrutura / Imagem", está relacionado ao construto "reputação acadêmica", que é apresentado por Johnston (1995) e Joseph e Joseph (1997). Ao analisar as variáveis intrínsecas a esse fator, cabe destacar que os relacionamentos entre alunos e a troca de ideias são considerados meios de facilitação da aprendizagem, e em consequência se refletem positivamente na imagem do curso e da IES.

O mesmo ocorre com o fator (F3), "Planejamento e desenvolvimento do curso", que ficou evidenciado na pesquisa como sendo o fator de maior importância devido às altas cargas fatoriais. É visível que a instituição necessita de uma maior atenção quanto à coordenação de alguns programas e ao cumprimento dos cronogramas de aula, que deixam margem para o descontentamento dos alunos. Destaca-se, também, nesse fator, que o conjunto de disciplinas deve ser articulado entre si, com o intuito de formar um arcabouço teórico e aplicável, compatível com as necessidades de formação de cada área específica, o que vai ao encontro de ideias de outros pesquisadores (HILL, 1995; JOSEPH, JOSEPH, 1997). 
O quarto e o quinto fatores (F4 e F5), denominados "Atendimento" e "Ambiente de ensino", atestam a importância do suporte e da infraestrutura disponíveis aos alunos, estando relacionados ao construto "tangibilidade" proposto por Parasuraman, Zeithaml e Berry (1985), que abordam as evidências físicas como instalações, equipamentos e pessoal. Observa-se que as variáveis que compõem esses dois fatores são comuns a diversos estudos encontrados na literatura (HILL, 1995; JOSEPH, JOSEPH, 1997; SOHAIL, SHAIKH, 2004), tendo uma forte relação com o estudo desenvolvido por Johnston (1995).

Por último, o sexto fator (F6), "Relação custo versus benefícios", agrupou os atributos preço e forma de pagamento. Entende-se que, de uma forma geral, os alunos percebem que recebem um determinado nível de retorno em contrapartida ao valor pago (mensalidades).

Com base na análise dos fatores, no que se refere às preferências dos alunos de pós-graduação lato sensu, ficou nítida a preocupação com a construção de conhecimentos e troca de experiências, com posturas e formas de interação adequadas dos professores com a turma e com a titulação (formação e capacitação) dos professores, entendidos como profissionais com competências técnicas ou científicas em uma determinada área de conhecimento.

Com base nas análises, de um modo geral, no que se refere às preferências dos alunos, ficou nítida a preocupação da absorção (construção) de conhecimentos, com posturas e formas de interação dos professores com a turma, e com a titulação dos professores capacitados, entendidos como profissionais com competências técnicas ou científicas em uma determinada área de conhecimento. Além desses aspectos, destacados como essenciais na decisão dos pesquisados, outros aspectos, como a cortesia dos funcionários e a conveniência dos horários de aula, ajudam a complementar o entendimento dos alunos como acolhimento e preocupação da instituição com o seu cliente.

A análise da satisfação geral dos alunos dos cursos de pós-graduação lato sensu da IES tem sua variação explicada por 12 atributos em 69,6\%, destacando que praticamente todos os fatores identificados na análise fatorial estão representados no modelo. Portanto, há evidências que nos remetem ao estudo realizado por Anderson e Mittal (2000), que evidenciou a relação entre o nível de qualidade, a satisfação, a retenção e a lealdade de clientes com a lucratividade e a rentabilidade das empresas, no sentido de atingirem maiores níveis de sustentabilidade e competitividade perante o mercado.

Outro aspecto evidenciado neste estudo, ao se tratar de qualidade de serviços de ensino superior, é que o aluno (cliente) deve ser visto como um participante ativo do processo de aprendizagem em vez 
de um simples "produto" (ou resultado final), e que as dimensões da qualidade podem variar de acordo com os seus interesses particulares ou situações e ambientes em estudo (LOPES, LEITE, LEITE, 2007; WIKLUND e outros, 2003). É importante ressaltar que, por falta de conhecimento ou informações, nem sempre o cliente está apto a reconhecer a qualidade técnica de um serviço. E, por esse motivo, a dimensão funcional da qualidade é mais facilmente apreciada ou avaliada pelo cliente (TÉBOUL, 2002).

Os modelos da satisfação geral, da possibilidade de recompra e da indicação a terceiros resultantes neste estudo reforçam a afirmação de Heskett, Sasser Jr. e Schlesinger (2002) de que, ao se tratar de serviços educacionais, especificamente, a propaganda boca a boca positiva se torna um benefício relevante para a satisfação dos clientes, sendo que clientes satisfeitos estão mais propensos a fazer recomendações para clientes potenciais. As recomendações de pessoas próximas, e de confiança, podem diminuir os riscos percebidos e aliviar as tensões intrínsecas ao processo de tomada de decisão na escolha de uma IES.

Os resultados encontrados nesta pesquisa sugerem as seguintes possíveis implicações gerenciais a serem adotadas pela Coordenadoria de Pós-Graduação Lato Sensu da IES em estudo: indicação de um representante de cada Centro Acadêmico para o Comitê de Pós-Graduação Lato Sensu, avaliação detalhada da situação atual dos programas (cursos), criação de um "escritório da qualidade" da Pós-Graduação Lato Sensu, implantação de um setor de relacionamento com os alunos e criação e consolidação de uma cultura de serviço.

É possível citar, como limitações do trabalho, a não realização de cruzamentos de variáveis que poderiam enriquecer a análise dos dados. Outra limitação é o fato de se ter adotado somente a análise fatorial para verificar os fatores que compõem as dimensões da qualidade dos serviços prestados, quando poderia ter sido feito um refinamento completo do instrumento de coleta de dados, que envolve outras etapas a serem cumpridas, a redução dos itens do questionário, novas análises e refinamento da escala. Além disso, o fato de a pesquisa quantitativa ter sido realizada por meio de uma coleta de dados do tipo corte transversal único, não permitindo que se verificassem mudanças na percepção dos respondentes longitudinalmente, e a dúvida sobre a existência de outros fatores que influenciariam o momento de decisão por um determinado curso e/ou IES.

Assim sendo, outros pesquisadores são encorajados a utilizar o presente estudo como base para novas aplicações e situações de pesquisa. Como sugestões para pesquisas futuras, podem-se citar: replicação do mesmo estudo em outras IES (públicas e/ou privadas); replicação nos demais campi da 
IES em estudo; replicação da mesma pesquisa, no mesmo contexto, permitindo uma comparação longitudinal dos resultados; verificação da implementação de estratégias a partir dos dados levantados, e melhoria no nível de competitividade institucional e no nível de satisfação geral dos alunos. Embora sejam contribuições inerentes a um ambiente de pesquisa particular, com suas especificidades, há a possibilidade de se ampliar a discussão e de se replicarem pesquisas similares em outros contextos, gerando melhorias na qualidade dos cursos de pós-graduação lato sensu no Brasil, aumentando o nível de satisfação dos alunos e estimulando a sua retenção junto às IES.

\section{REFERÊNCIAS}

ALBRECHT, K. Customer value. Executive Excellence, v. 11, n. 9, 1994.

ALBRECHT, K; BRADFORD, L. J. Serviços com qualidade: a vantagem competitiva. 1. ed. São Paulo: Makron Books, 1992.

ANDERSON, E. W; FORNELl, C; LEHMANN, D. R. Perceived quality, customer satisfaction, market share, and profitability. Working Paper. National Quality Research Center. Ann Harbor, MI: The University of Michigan, 1992.

ANDERSON, E. W; FORNELL, C; LEHMANN, D. R. Customer satisfaction, market share and profitability: findings from Sweden. Journal of Marketing, v. 58, n. 3, p. 53-66, 1994.

ANDERSON, J; MITTAL, V. Strengthening the satisfaction-profit chain. Journal of Service Research, v. 3, n. 2, p. 107-120, 2000.

BARDIN, L. Análise de conteúdo. Lisboa: Edições 70, 2004.

BLOEMER, J. M. M; KASPER, H. D. P. The complex relationship between consumer satisfaction and brand loyalty. Journal of Economic Psychology, v. 16, n. 2, p. 311-329, 1995. 
FÓRUM - IDENTIFICAÇÃO DAS DIMENSÕES DA QUALIDADE EM SERVIÇOS: UM ESTUDO APLICADO EM UMA INSTITUIÇÃO DE ENSINO SUPERIOR

Luciene Eberle - Gabriel Sperandio Milan - Fernanda Lazzari

BOLTON, R; DREW, J. H. A multi-stage model of customers' assessments of service quality and value. Journal of Consumer Research, v. 17, n. 4, p. 375-384, 1991.

BOULDING, W; KALRA, A; STAELIN, R; ZEITHAML, V. A. A dynamic process model of service quality: from expectations to behavioral intentions. Journal of Marketing Research, v. 30, n. 1, p. 7-27, 1993.

BRADY, M. K; CRONIN JR, J; BRAND, R. R. Performance-only measurement of service quality: a replication and extension. Journal of Business Research, v. 55, n.1, p. 17-31, 2002.

CÂMARA DA INDÚSTRIA, Comércio e Serviços de Caxias do Sul (CICS). Dados estatísticos. Disponível em: http://www.cic.estatísticas.com.br.htm. Acesso em 28.10.2008.

CARMAN, J. M. Consumer perceptions of service quality: an assessment of the ServQual dimensions. Journal of Retailing, v. 66, n. 1, p. 33-35, 1990.

CERVO, A. L; BERVIAN, P. A. Metodologia científica. 5. ed. São Paulo: Prentice Hall, 2002.

CHENG, Y. C. A CMI-triplization paradigm for reforming education in the new millennium. International Journal of Educational Management, v. 14, n. 4, p. 156-174, 2000.

CHURCHILL JR, G. A. A paradigm for developing better measures of marketing constructs. Journal of Marketing Research, v. 16, n. 1, p. 64-73, 1979.

COOPER, D. R; SCHINDLER, P. S. Métodos de pesquisa em administração. 7. ed. Porto Alegre: Bookman, 2003.

CRONIN JR, J; TAYLOR, S. A. Measuring service quality: a reexamination and extension. Journal of Marketing, v. 56, n. 3, p. 55-68, 1992. 
FÓRUM - IDENTIFICAÇÃO DAS DIMENSÕES DA QUALIDADE EM SERVIÇOS: UM ESTUDO APLICADO EM UMA INSTITUIÇÃO DE ENSINO SUPERIOR

Luciene Eberle - Gabriel Sperandio Milan - Fernanda Lazzari

CRONIN JR, J; TAYLOR, S. A. ServPerf versus ServQual: reconciling performance-based and perceptions-minus-expectations measurement of service quality. Journal of Marketing, v. 58, n. 1, p. 125-131, 1994.

DAGGER, T. S; SWEENEY, J. C; JOHNSON, L. W. A hierarchical model of health service quality: scale development and investigation of an integrated model. Journal of Service Research, v. 10, n. 2, p. 123-142, 2007.

DENTON, D. K. Qualidade em serviços: o atendimento ao cliente como fator de vantagem competitiva. São Paulo: Makron Books, 1990.

DUTRA, H. F. O; OlIVEIRA, P. A. S; GOUVEIA, T. B. Avaliando a qualidade de serviço numa instituição de ensino superior. In: ENCONTRO DA ASSOCIAÇÃO NACIONAL DE PÓSGRADUAÇÃO E PESQUISA EM ADMINISTRAÇÃO, 22, 2002, Foz do Iguaçu. Anais. Foz do Iguaçu: ANPAD, 2002.

ESPARTEL, L. B. Um estudo longitudinal da lealdade do cliente e de seus antecedentes. Tese de Doutorado em Administração pelo Programa de Pós-Graduação, Escola de Administração da Universidade do Rio Grande do Sul, 2005.

FINN, A. Are marketers deluding themselves with reported coefficient alphas? Paper submitted for possible presentation at EMAC 2001. Rethinking Marketing Research Track, 2000. Disponível em: www.base.unisinos.br/pdf/86.pdf.

FORNELL, C. National and corporate customer satisfaction indexes: a presentation at the World Quality Day. Amsterdam: World Trade Center, 1991.

FORNELL, C. A national customer satisfaction barometer: the Swedish experience. Journal of Marketing, v. 56, n. 1, p. 6-21, 1992. 
FÓRUM - IDENTIFICAÇÃO DAS DIMENSÕES DA QUALIDADE EM SERVIÇOS: UM ESTUDO APLICADO EM UMA INSTITUIÇÃO DE ENSINO SUPERIOR

Luciene Eberle - Gabriel Sperandio Milan - Fernanda Lazzari

FREITAS, A. L. P; RODRIGUES, S. G. A estrutura do processo de autoavaliação de IES: uma contribuição para a gestão educacional. In: ENCONTRO NACIONAL DE ENGENHARIA DE PRODUÇÃO, 23, 2003, Ouro Preto: Anais. Ouro Preto: ENEGEP, 2003.

GARVIN, D. A. Competing on the eight dimensions of quality. Harvard Business Review, v. 65, n. 6, p. 101-110, 1987.

GATES, R; MCDANIEL JR, C. Fundamentos de pesquisa de marketing. 4. ed. Rio de Janeiro: LTC, 2005 .

GIBSON, C. B. Quality of team service: the of field independent culture, quality orientation, and quality improvement focus. Small Group Research, v. 34, n. 5, p. 619-646, 2003.

GREY, C. Reinventing business schools: the contribution of critical management education. Academy of Management Learning and Education, v. 3, n. 2, p. 178-186, 2004.

GRIFFIN, J. Customer Loyalty: How To Earn It, How To Keep It. San Francisco: Jossey-Bass, 2002.

GRÖNROOS, C. A service quality model and its marketing implications. European Journal of Marketing, v. 18, n. 4, p. 36-44, 1984.

GRÖNROOS, C. Service Management and Marketing: Managing the Moment of Truth in Service Competition. Lexington, MA: Free Press, Lexington Books, 1990.

GRÖNROOS, C. Marketing services: the case of a missing product. Journal of Business \& Industrial Marketing, v. 13, n. 4/5, p. 322-338, 1998.

GUMMESSON, E. Service management: an evaluation and the future. International Journal of Service Industry Management, v. 5, n. 1, p. 77-96, 1994. 
FÓRUM - IDENTIFICAÇÃO DAS DIMENSÕES DA QUALIDADE EM SERVIÇOS: UM ESTUDO APLICADO EM UMA INSTITUIÇÃO DE ENSINO SUPERIOR

Luciene Eberle - Gabriel Sperandio Milan - Fernanda Lazzari

HAIR JR, J. F; ANDERSON, R. E; TATHAM, R. L; BLACK, W. C. Análise multivariada de dados. 5. ed. Porto Alegre: Bookman, 2005.

HESKETT, J. L; SASSER JR, W. E; SCHLESINGER, L. A. Lucro na prestação de serviços. Rio de Janeiro: Campus, 2002.

HILL, F. M. Managing service quality in higher education. Quality Assurance in Education, v. 3, n. 3, p. 10-21, 1995.

HUDSON, S; HUDSON, P; MILLER, G. A. The measurement of service quality in the tour operating sector: a methodological comparison. Journal of Travel Research, v. 42, n. 3, p. 305-312, 2004.

JOHNSON, R. A; WICHERN, D. W. Applied Multivariate Statistical Analysis. 5. ed. Upper Saddle River, NJ: Prentice Hall, 2002.

JOHNSTON, R. The determinants of service quality: satisfiers and dissatisfiers. International Journal of Service Industry Management, v. 6, n. 5, p. 53-71, 1995.

JOSEPH, M; JOSEPH, B. Service quality in education: a student perspective. Quality Assurance in Education, v. 5, n. 1, p. 15-21, 1997.

KOTLER, P; FOX, K. Marketing estratégico para instituições educacionais. São Paulo: Atlas, 1994.

KUMAR, V; AAKER, D. A; DAY, G. S. Essentials of Marketing Research. New York: John Wiley \& Sons, 1999.

LLUSAR, J. C. B; ZORNOZA, C. C. Validity and reliability in perceived quality measurement models: an empirical investigation in Spanish ceramic companies. International Journal of Quality and Reliability Management, v. 17, n. 8, p. 899-918, 2000. 
FÓRUM - IDENTIFICAÇÃO DAS DIMENSÕES DA QUALIDADE EM SERVIÇOS: UM ESTUDO APLICADO EM UMA INSTITUIÇÃO DE ENSINO SUPERIOR

Luciene Eberle - Gabriel Sperandio Milan - Fernanda Lazzari

LOPES, H. E. G; LEITE, R. S; LEITE, D. S. O que realmente importa? Um estudo sobre os fatores determinantes da qualidade percebida no curso superior de uma instituição do centro-oeste de Minas Gerais. Revista Eletrônica de Administração, v. 13, n. 2, 2007.

MADU C. N; KUEI, C. Customer-centric six sigma quality and reliability management. International Journal of Quality \& Reliability Management, v. 20, n. 8, p. 954-964, 2003.

MALHOTRA, N. K. Pesquisa de marketing. 4. ed. Porto Alegre: Bookman, 2006.

MARCHETTI, R. Z; PRADO, P. Avaliação da satisfação do consumidor utilizando o PLS: um modelo aplicado ao setor elétrico brasileiro. In: ENCONTRO DA ASSOCIAÇÃO NACIONAL DE PÓSGRADUAÇÃO E PESQUISA EM ADMINISTRAÇÃO, 25, 2001, Campinas. Anais. Campinas: ANPAD, 2001.

MEYER JR, V; LOPES, M. C. B. Planejamento formal e seus resultados: um estudo de caso de universidades. In: SEMINÁRIO DE PESQUISA EM EDUCAÇÃO DA REGIÃO SUL, 5, 2004, Curitiba. Anais. Curitiba: Anped-Sul, 2004.

MILAN, G. S. A prática do marketing de relacionamento e a retenção de clientes: um estudo aplicado em um ambiente de serviços. Tese de Doutorado em Engenharia da Produção, Escola de Engenharia, Universidade Federal do Rio Grande do Sul. Porto Alegre: UFRGS, 2006.

MILAN, G. S; TREZ, G. Pesquisa de satisfação: um modelo para planos de saúde. RAE-eletrônica, v. 4, n. 2, 2005 .

MILAN, G. S; TREZ, G; MAIOLI, F. C. Dimensões de satisfação em serviços: o caso de uma instituição de ensino superior. In: CONSEJO LATINOAMERICANO DE ESCUELAS DE ADMINISTRACIÓN, 40, 2005, Santiago de Chile: Anais. Santiago de Chile: Cladea, 2005.

OLIVER, R. L. Whence consumer loyalty? Journal of Marketing, v. 63, n. 4, p. 33-44, 1999. 
FÓRUM - IDENTIFICAÇÃO DAS DIMENSÕES DA QUALIDADE EM SERVIÇOS: UM ESTUDO APLICADO EM UMA INSTITUIÇÃO DE ENSINO SUPERIOR

Luciene Eberle - Gabriel Sperandio Milan - Fernanda Lazzari

OLIVER, R. L. Satisfaction: A Behavioral Perspective on the Consumer. 2. ed. New York: Irwin/McGraw-Hill, 2009.

PARASURAMAN, A; ZEITHAML, V. A; BERRY, L. L. A conceptual model of service quality and its implications for future research. Journal of Marketing, v. 49, n. 4, p. 41-50, 1985.

PARASURAMAN, A; ZEITHAML, V. A; BERRY, L. L. ServQual: a multiple-item scale for measuring consumer perception of service quality. Journal of Retailing, v. 64, n. 1, p. 12-40, 1988.

PESTANA, M. H; GAGEIRO, J. N. Análise de dados para ciências sociais. 4. ed. Lisboa: Sílabo, 2005.

RAYKOV, T. Coefficient alpha and composite reliability with interrelated nonhomegeneous items. Applied Psychological Measurement, v. 22, n. 4, p. 375-385, 1998.

REICHHELD, F. F. A estratégia da lealdade. Rio de Janeiro: Campus, 1996.

REICHHELD, F. F; MARKEY JR, R. G; HOPTON, C. The loyalty effect: the relationship between loyalty and profits. European Business Journal, v. 12, n. 3, p. 134-139, 2000.

REICHHELD, F. F; SASSER JR, W. E. Zero defections: quality comes to service. Harvard Business Review, v. 68, n. 5, p. 105-111, 1990.

RIBEIRO, J. L. D; MILAN, G. S. Planejando e conduzindo entrevistas individuais. In: RIBEIRO, J. L. D; MILAN, G. S. (Eds) Entrevistas individuais: teoria e aplicações. Porto Alegre: FEENG/UFGRS, 2004. cap. 1, p. 9-22.

RODRIGUES, C. M. C; RIBEIRO, J. L. D; MILAN, G. S. A condução da avaliação institucional em uma universidade comunitária. In: RIBEIRO, J. L. D; MILAN, G. S. (Eds) Entrevistas individuais: teoria e aplicações. Porto Alegre: FEENG/UFGRS, 2004. cap. 5, p. 85-106. 
FÓRUM - IDENTIFICAÇÃO DAS DIMENSÕES DA QUALIDADE EM SERVIÇOS: UM ESTUDO APLICADO EM UMA INSTITUIÇÃO DE ENSINO SUPERIOR

Luciene Eberle - Gabriel Sperandio Milan - Fernanda Lazzari

ROSSI, C. A. V; SLONGO, L. A. Pesquisa de satisfação de clientes: o estado da arte e proposição de um método brasileiro. Revista de Administração Contemporânea, v. 2, n. 1, 1998.

ROWLEY, J. Beyond service quality dimensions in higher education and towards a service contract. Quality Assurance in Education, v. 5, n. 1, p. 7-14, 1997.

RUST, R. T; ZAHORIK, A. J. Customer satisfaction, customer retention, and market share. Journal of Retailing, v. 69, n. 2, p. 139-215, 1993.

SASSER JR, W. E; JONES, T. O. Why satisfied customers defect. Harvard Business Review, v. 12, n. 6, p. 88-89, 1995.

SIQUEIRA, R. P; CARVALHO, J. L. F. Qualidade do serviço educacional prestado por escolas de Administração: confronto entre uma universidade pública e uma faculdade privada. In: ENCONTRO DA ASSOCIAÇÃO NACIONAL DE PÓS-GRADUAÇÃO E PESQUISA EM ADMINISTRAÇÃO, 30, 2006, Salvador. Anais. Salvador: ANPAD, 2006.

SOHAIL, M. S; SHAIKH, N. M. Quest for excellence in business education: a study of student impressions of service quality. The international Journal of Educational Management, v. 18, n. 1, p. 58-65, 2004.

SRIKANTHAN, G; DALRYMPLE, J. Developing alternative perspectives for quality in higher education. The International Journal of Educational Management, v. 17, n. 2/3, p. 126-136, 2003.

TEAS, R. K. Expectations, performance evaluation and consumer's perceptions of quality. Journal of Marketing, v. 57, n. 4, p. 18-34, 1993.

TEAS, R. K. Expectations as a comparison standard in measuring service quality: an assessment of a reassessment. Journal of Marketing, v. 58, n. 1, p. 132-139, 1994.

TÉBOUL, J. A era dos serviços. Rio de Janeiro: Qualitymark, 2002. 
FÓRUM - IDENTIFICAÇÃO DAS DIMENSÕES DA QUALIDADE EM SERVIÇOS: UM ESTUDO APLICADO EM UMA INSTITUIÇÃO DE ENSINO SUPERIOR

Luciene Eberle - Gabriel Sperandio Milan - Fernanda Lazzari

TURNER, P. K; KRIZEK, R. L. A meaning-centered approach to customer satisfaction. Management Communication Quarterly, v. 20, n. 2, p. 115-147, 2006.

VAVRA, T. G; PRUDEN, D. R. Using aftermarketing to maintain a customer base. Discount Merchandiser, v. 35, n. 5, p. 86-88, 1995.

WELSH, J. F; DEY, S. Quality measurement and quality assurance in higher education. Quality Assurance in Education, v. 10, n. 1, p. 17-25, 2002.

WIKLUND, H; KLEFSJO, B; WIKLUND, P. S; EDUARDSSON, B. Innovation TQM is Swedish higher education institutions - possibilities and pitfalls. The TQM Magazine, v. 15, n. 2, p. 99-107, 2003.

WRAY, N; MARKOVIC, M; MANDERSON, L. Researcher saturation: the impact of data triangulation and intensive-research practices on the researcher and qualitative research process. Journal Qualitative Health Research, v. 17, n. 10, p. 1392-1402, 2007.

ZEITHAML, V. A; BERRY, L. L; PARASURAMAN, A. The behavioral consequences of service quality. Journal of Marketing, v. 60, n. 2, p. 31-46, 1996.

ZEITHAML, V. A; PARASURAMAN, A; BERRY, L. L. Delivering Quality Service: Balancing Customer Perceptions and Expectations. New York: Free Press, 1990. 